\title{
Population growth across heterogeneous environments: effects of harvesting and age structure
}

\author{
Joël M. Durant ${ }^{1, *}$, Manuel Hidalgo ${ }^{1,5}$, Tristan Rouyer ${ }^{1,6}{ }^{\text {, Dag } Ø . ~ H j e r m a n n ~}{ }^{1,7}$, \\ Lorenzo Ciannelli ${ }^{2}$, Anne Maria Eikeset ${ }^{1}$, Natalia Yaragina ${ }^{3}$, N. C. Stenseth ${ }^{1,4}$ \\ ${ }^{1}$ Centre for Ecological and Evolutionary Synthesis (CEES), Department of Biosciences, University of Oslo, \\ PO Box 1066 Blindern, 0316 Oslo, Norway \\ ${ }^{2}$ College of Earth, Ocean and Atmospheric Sciences, Oregon State University, 104 COAS Administration Building, Corvallis, \\ Oregon 97331-5503, USA \\ ${ }^{3}$ Knipovich Polar Research Institute of Marine Fisheries and Oceanography (PINRO), 6 Knipovich Street, Murmansk 183038, Russia \\ ${ }^{4}$ Institute of Marine Research, Flødevigen Marine Research Station, 4817 His, Norway \\ ${ }^{5}$ Present address: Instituto Español de Oceanografía, Centre Oceanogràfic de les Balears, Moll de Ponent s/n, 07015 Palma, Spain \\ ${ }^{6}$ Present address: Laboratoire Ressources Halieutiques de Sète, Ifremer, Station de Sète, Av. Jean Monnet, \\ BP 171 - 34203 Sète Cedex, France \\ ${ }^{7}$ Present address: Norwegian Institute for Water Research (NIVA), Gaustadalléen 21, 0349 Oslo, Norway
}

\begin{abstract}
Population growth is affected by several factors such as climate, species interaction and harvesting pressure. However, additional complexity can arise if fishing increases the sensitivity to environmental variability. To predict the effects of fisheries and climate on marine populations, there is a need for improved understanding of how they affect key ecological processes such as population growth. In this study, we used a comparative approach investigating commercially fished species across different ecosystems: the Norwegian Sea-Barents Sea (Northeast Arctic cod), the North Sea (North Sea cod), the Atlantic Ocean (European hake), the Mediterranean Sea (European hake), and the Gulf of Alaska and Bering Sea (walleye pollock). Our objective was to compare the effects of commercial fisheries, age structure and environmental variability on population growth rate. We show that although all stocks experienced a decline in abundance, only 3 of them showed a concomitant decreasing trend in generation time (South Atlantic hake, North Atlantic hake and Northeast Arctic cod), suggesting a fishing-induced erosion in their age structure. Intra-specific analysis shows that changes in generation time triggered an increase in the relative contribution of recruitment to population growth. Furthermore, the contribution from recruitment to population growth changes due to large-scale climate indices or regional-scale environmental covariates, such as sea temperature. This study illustrates how and where the interaction between large-scale ecological patterns and regional/short-scale processes are important for designing management regulations.
\end{abstract}

KEY WORDS: Barents Sea $\cdot$ Mediterranean Sea $\cdot$ Bering Sea $\cdot$ Cod $\cdot$ Gadus morhua $\cdot$ European hake · Merluccius merluccius $\cdot$ Pollock $\cdot$ Theragra chalcogramma $\cdot$ Leslie matrix $\cdot$ Fisheries

\section{INTRODUCTION}

Population dynamics in general and population growth in particular is affected by several factors such as climate, species interactions and harvesting pressure. Harvesting pressure has been proposed as a possible pathway for an increasing sensitivity of mar- ine fish populations to climate (e.g. Rouyer et al. 2011, but see Ottersen et al. 2013, this Theme Section). Thus, in addition to the obvious consequences of high and often size-selective mortality from commercial fishing (loss of older and larger individuals), interacting effects between exploitation and environment influence fish stock production (Hsieh et al. 2010). 
These complex interactions may also depend on the life cycle characteristics of the species studied. The life cycles of many fish species in high-latitude seas have adapted to a strong pulse of primary productivity in spring, short summers, and partial ice cover during parts of the year. Also, food resources and suitable habitat for young are often spatially clustered. For these fish species, evolutionary pressure pushes towards developing adaptive strategies for the timing of life cycle events (e.g. reproduction), the length of spawning and feeding migrations, and the use of environmental cues (e.g. photoperiod and temperature). Analogously, some oligotrophic systems, such as the Mediterranean Sea, may display similar adaptive life history strategies to match the favourable environmental conditions occurring at small spatial and temporal scales (Hidalgo et al. 2009).

Specific strategies, such as greater longevity and bet-hedging, allow species inhabiting high latitudes to survive until encountering favourable conditions for reproduction within a particular temporal window, whereas more temperate/tropical species typically have more opportunistic reproduction strategies (Murphy 1968, Fromentin \& Fonteneau 2001) with faster traits (earlier maturation, faster growth, reduced age structure). For instance, cod stocks display a broad range of life history traits related to the mean temperature of their environment (Brander 1995). Since high-latitude species are more sensitive to environmental variability than temperate/tropical species and can display broad age distributions, which are potentially affected by exploitation (Miller et al. 1991, Brunel \& Boucher 2006, Rouyer et al. 2011), comparing different species inhabiting across the latitudinal gradient will provide insight into important aspects of such strategies.

Fisheries management challenges are increased by climate change (Le Maho \& Durant 2011). Indeed, when looking at the effect of harvesting on fish stocks (e.g. reduction of abundance, distribution, biodiversity or genetic diversity; age truncation; juvenescence) fisheries have also to take into account the effect of climate change on the fish population dynamics and trophic interactions (Cury et al. 2008). However, separating the environmental effects on marine fish stock dynamics from those of exploitation has been a long-term challenge. In this study we investigated how climate, fishing and internal population properties such as age structure operate across different ecosystems. Specifically, we explored how external forcing (climate and fishing) and recruitment modulate the population dynamics of fish within different environments. To do so, we calculated the population growth based on yearly Leslie matrices and its elasticity to recruitment of 7 commercially exploited stocks: the European hake Merluccius merluccius in the Northeast Atlantic Ocean (Southern and Northern) and the Mediterranean Sea, the cod Gadus morhua in the North Sea and Barents Sea, and the pollock Theragra chalcogramma in the Bering Sea and the Gulf of Alaska. The elasticity is the percentage change in output for a certain percentage change in input; it illustrates the changes in population growth as a ratio of changes in either survival or recruitment. This tells us where the population is more sensitive to modification of its vital rates. Modeling the elasticities for different stocks is expected to give new insights into how recruitment that is affected by climate, age structure, or fishing pressure in turn affects the population growth rate. Our aim is to explore the differences produced by external and internal drivers contributing to the variability in population growth rate across different ecosystems. To do so, we compared stocks with different fishing pressure (from fished to overfished) and from different latitudes (high to intermediate latitudes).

\section{MATERIALS AND METHODS}

The fish data used (age-specific abundance, fishing mortality, and maturity ogives) were extracted from assessments made using virtual population analyses (VPA; i.e. based on commercial catch data, Lassen \& Medley 2001 and references therein for methods) tuned to the survey data. From these data we calculated the average fishing mortality $(F)$ for each year. Table 1 summarizes the data used. Fig. 1 displays the general geographical localisation of each stock.

\section{European hake Merluccius merluccius}

The European hake (here called hake) (Fig. S1 in the Supplement at www-int-res.com/articles/suppl/ m480p277_supp.pdf) is a groundfish species inhabiting the North Atlantic European coast (from north of Norway to the Mauritanian waters) and the entire Mediterranean Sea. Three areas (Fig. 1) for which age-structured information on hake was available are considered in this study (FAO-GFCM 2009, ICES 2009): 2 in the Atlantic Ocean referred to (for management purposes) as North Atlantic stock (NA hake) and South Atlantic stock (SA hake), and one in the Mediterranean Sea around the Balearic Islands 
Table 1. Data description of the stocks considered. NEA: Northeast Arctic; NS: North Sea; EBS: Eastern Bering Sea; GOA: Gulf of Alaska; NA: Northern Atlantic; SA: Southern Atlantic; BI: Balearic Islands; VPA: virtual population analysis; NAO: North Atlantic Oscillation; GULF: annual mean values of the Gulf Stream; PDO: Pacific Decadal Oscillation; UI: upwelling index;

IDEA: hydro-climatic index based on the air-sea heat fluxes in the Gulf of Lions during winter. +: data used; -: no data

\begin{tabular}{|c|c|c|c|c|c|c|c|}
\hline & NEA cod & NS cod & EBS pollock & GOA pollock & NA hake & SA hake & BI hake \\
\hline VPA years $^{\mathrm{a}}$ & 1946-2010 & $1963-2011$ & 1964-2010 & 1961-2010 & 1978-2008 & 1982-2008 & 1980-2008 \\
\hline Years used & $1946-2000$ & $1963-2007$ & 1982-2004 & 1983-2002 & $1979-2003$ & 1983-2003 & 1981-2004 \\
\hline \multicolumn{8}{|c|}{ Population life history variables } \\
\hline Age range assessed (yr) & $3-12+$ & $1-7+$ & $1-10+$ & $2-10+$ & $0-8+$ & $0-8+$ & $0-5+$ \\
\hline Maturity ogives & Annual & Mean & Mean & Mean & Annual & Annual & Mean \\
\hline Recruits number & + & + & + & + & + & + & + \\
\hline Elasticity & + & + & + & + & + & + & + \\
\hline \multicolumn{8}{|l|}{ Environmental variables } \\
\hline Temperature $\left({ }^{\circ} \mathrm{C}\right)$ & + & + & + & + & + & + & + \\
\hline $\mathrm{NAO}$ & + & + & - & - & + & + & + \\
\hline GULF & - & - & - & - & + & + & - \\
\hline PDO & - & - & + & + & - & - & - \\
\hline UI & - & - & - & - & - & + & - \\
\hline IDEA & - & - & - & - & - & - & + \\
\hline Fishing mortality $(F)$ & + & + & + & + & + & + & + \\
\hline
\end{tabular}

(BI hake). Hake is regarded as overharvested in all 3 areas (ICES 2009). For each stock, $F$ over age was calculated for the most harvested age classes of each area (based on the $F$ at age profile): $F_{2-5}$ for SA hake, $F_{2-6}$ for NA hake and $F_{2-4}$ for BI hake (the subscripts indicate the ages used in yr).

\section{Cod Gadus morhua of the Lofoten-Barents Sea and North Sea systems}

The Northeast Arctic (NEA) cod population inhabiting the Barents Sea is at present the world's largest stock of Atlantic cod (Worm \& Myers 2003) (Fig. S2 in the Supplement). NEA cod spawns along the Norwegian coast. The North Sea (NS) cod is another cod population whose abundance has declined steadily since the 1960s (ICES 2011b, Hjermann et al. 2013, this Theme Section). Age-structured information on NEA cod is available from 1946 (ICES 2011a) and for NS cod from 1963 (ICES 2011b). For NS cod, proportion of mature individuals per age was given as a mean per age class. Average fishing mortality was calculated for age groups 5-10 $\left(F_{5-10}\right)$ for NEA cod and age groups $2-4\left(F_{2-4}\right)$ for NS cod.

\section{Walleye pollock Theragra chalcogramma of the Bering Sea and Gulf of Alaska systems}

Walleye pollock (Fig. S2 in the Supplement) currently constitutes the second largest single-species fishery in the world. Information on Eastern Bering Sea (EBS) pollock and Gulf of Alaska (GOA) pollock year-class strength is available back to 1964 (Ianelli et al. 2009, Dorn et al. 2010). However, since catch data are uncertain prior to 1982, we used data only from 1982 onwards for EBS pollock and 1983 onwards for GOA pollock. For EBS pollock, the proportion of matures per age was given as a mean per age class. For GOA pollock, annual estimates of the agespecific proportion of mature individuals was available from 1983 onward. Fishing mortality is given by $F_{6-10}$ and $F_{5-8}$ for EBS and GOA pollock, respectively.

\section{Environmental data}

Climate indices and regional-scale hydroclimatic variables were used as potential environmental drivers. Climate indices capture complex spatio-temporal variability into a simple metric and integrate largerscale climate processes and their variability (Hallett et al. 2004). They have been shown to be good predictors for biological processes because they reduce complex space and time climatic variability into simple measures (Stenseth et al. 2003). We selected a relevant large-scale climate index for each studied stock. For the NA hake stock, we used annual mean values of the Gulf Stream index (GULF; http:// web.pml.ac.uk/gulfstream/data.htm), which is the first principal component of the position of the North Wall of the Gulf Stream (Taylor 1995). For the SA hake stock we used an upwelling index (UI) obtained from 

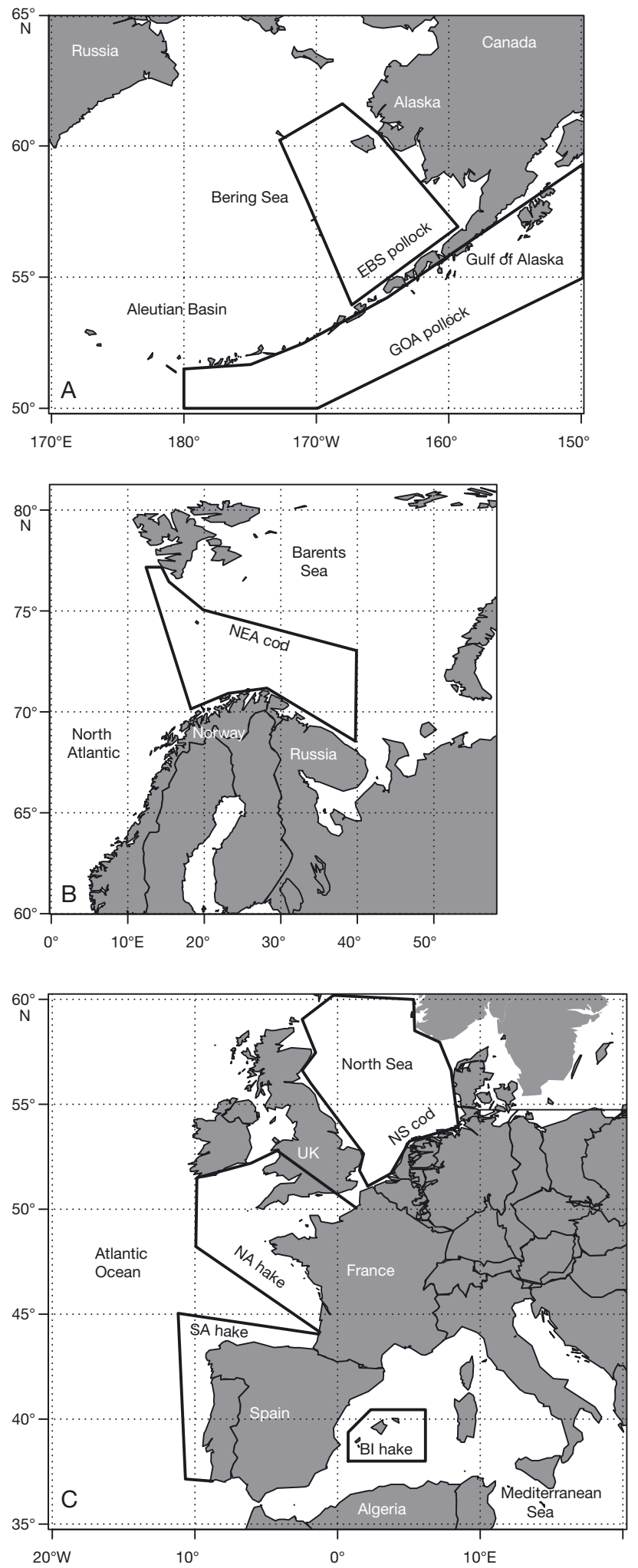

Fig. 1. Geographic location of the 7 stocks analysed. (A) Eastern Bering Sea (EBS) and Gulf of Alaska (GOA) pollock stocks. (B) Northeast Arctic (NEA) cod stock. (C) Northern Atlantic (NA), Southern Atlantic (SA) and Balearic Islands (BI) hake stocks the monthly mean of daily offshore Ekman transport values $\left(-Q_{x i} \mathrm{~m}^{3} \mathrm{~s}^{-1} \mathrm{~km}^{-1}\right)$ offshore of the NW Spanish peninsula (see 'Methods' in Lavín et al. 1991). For the BI hake we used the IDEA index, a mesoscale (regional) hydro-climatic index based on the air-sea heat fluxes in the Gulf of Lions during winter (Massutí et al. 2008, Monserrat et al. 2008). For the NEA and NS cod, we used the North Atlantic Oscillation calculated for winter months (wNAO) (Hurrell \& Deser 2009). For the EBS and GOA pollock we used the Pacific Decadal Oscillation calculated for winter months (wPDO).

Temperature was also used as a regional hydroclimatic variable potentially affecting the survival of early life stages of demersal species before settlement to the bottom. The temperature variables used have been reported to explain the dynamics for NA, SA and BI hake (Hidalgo et al. 2012), NEA (Hjermann et al. 2004) and NS cod (Hjermann et al. 2013), and GOA (Ciannelli et al. 2004) and EBS pollock (Mueter et al. 2011). Sea surface temperature (SST) for hake were obtained from the Climate Diagnostics Center (NCEP/NCAR) reanalysis fields (Kalnay et al. 1996) on a $1 \times 1$ degree grid and averaged over the area of each studied stock. Seasonal averages were calculated for each stock in winter (from December to February) and spring (from March to May) over each study area covering from early life stages survival to recruitment. For the Barents Sea we used yearly average sea temperature measured monthly at 0-200 m depth (ST) on the Russian Kola meridian transect $\left(33^{\circ} 30^{\prime} \mathrm{E}, 70^{\circ} 30^{\prime} \mathrm{N}\right.$ to $72^{\circ} 30^{\prime} \mathrm{N}$ ) (see references in Hjermann et al. 2004). Time series of temperature for the NS cod and pollock stocks have been extracted over the distribution area of each stock from the extended reconstructed SST (NOAA_ ERSST_V3) data set provided by the Physical Sciences Division of the NOAA Earth System Research Laboratory (www.esrl.noaa.gov/psd/). Data are available from 1960 to 2007 with $1 \times 1$ degree grid resolution for the cod from 1880 to 2009 and with $2 \times 2$ degree grid resolution for the pollock (based on the International Comprehensive Ocean-Atmosphere Data Set (ICOADS) Sea Surface Temperature data). The data were averaged as follows: North Sea, Long $51.5^{\circ}$ to $55.5^{\circ} /$ Lat $0.5^{\circ}$ to $4.5^{\circ}$ for March to May $\left(\mathrm{SST}_{\text {springi }}\right.$ Hjermann et al. 2013); Bering Sea, Long $-174^{\circ}$ to $-166^{\circ} /$ Lat $56^{\circ}$ to $60^{\circ}$ for April to July. For the Gulf of Alaska, we extracted summer temperature $\left(\mathrm{SST}_{\text {sum } 1}\right.$, Long $-164^{\circ}$ to $-162^{\circ} /$ Lat $50^{\circ}$ to $54^{\circ}$ for June-July-August) and winter temperature $\left(\mathrm{SST}_{\text {wint2, }}\right.$ Long $-164^{\circ}$ to $-160^{\circ} /$ Lat $56^{\circ}$ to $60^{\circ}$ for December-January-February). 


\section{Calculation of population growth and elasticity}

One way to reduce the complexity of age-structured population dynamics is to approach the question of population persistence through the use of Leslie matrix models (Leslie 1945, Caswell 2001, Hastings \& Botsford 2006). Leslie matrix models are agestructured population models that use estimates of demographic rates for different age or size classes to project population dynamics (Caswell 2001). Vital rates are summarized in an annual transition matrix A, which defines the population sizes in the following year $\left(\mathrm{n}_{t+1}\right)$ as the product of the matrix $\mathbf{A}$ and the current year's population size $\left(\mathrm{n}_{t}\right)$, where the $\mathrm{n}_{t}$ values are vectors defined by the number of individuals within each age class. The long-term (asymptotic) population growth rate, $r$, is given by the logarithm of the dominant eigenvalue $\lambda$ of $\mathbf{A}$ (Caswell 2001).

Here we compiled annual Leslie matrices $\mathbf{A}_{t}$ for each population studied. Note that $\mathbf{A}_{t}$ is compiled for the age structure measured in year $t$ (hence valid only for the time frame year $t$ to year $t+1$ ) as is the resulting yearly realized population growth rate, $r_{t}$.

For a given year, the transition matrix $\mathbf{A}_{t}$ is defined as follows:

$$
A_{t}=\left(\begin{array}{ccccc}
\mathrm{RS}_{0, t} & \mathrm{RS}_{1, t} & \mathrm{RS}_{2, t} & \ldots & \mathrm{RS}_{i \text { max }, t} \\
S_{1-0, t} & 0 & 0 & \ldots & 0 \\
0 & S_{2-1, t} & 0 & \ldots & 0 \\
\ldots & \ldots & \ldots & \ldots & \ldots \\
0 & 0 & 0 & S_{i \max -(\max -1), t} & 0
\end{array}\right)
$$

where $S_{i-(i-1), t}$ is the survival between age class $i$ at year $t$ and age class $i-1$ at year $t-1$, and $\mathrm{RS}_{i, t}$ is the recruitment success of year class $i$ at year $t . \mathrm{RS}_{i, t}$ is function of 2 components: the maturity rates and the proportion of survived recruits per age class.

An advantage of the Leslie matrix approach is the well-established derivation of elasticities of $r$ to the vital rates in A (Caswell 2001). The elasticity matrix (E) describes the proportional response of $r$ (through the first eigenvalue) to a proportional perturbation in the vital rates; in other words, it provides information on the relative contribution of vital rate(s) to the variations in $r_{t}$ (details can be found in Caswell 2001). However, A gives the asymptotic population growth rate (i.e. the first eigenvalue of $\mathbf{A}$ ), that is, the rate of growth of the population if the population has reached the stable age structure and if present environmental conditions were maintained indefinitely. Consequently, the asymptotic population growth can be biased at a short time scale for populations with no stable age structure due to environmental variations (e.g. large year-to-year variations in recruitment). In order to evaluate how recruitment affects spawning stock biomass and population numbers, we performed a transient elasticity (hereafter called elasticity, $\boldsymbol{e}_{t}$ ) analysis following the principles found in Caswell (2007). We used numerical methods based on simulating the population from year $t$ to year $t+X$. If we do such a simulation using the year-specific transition matrices $\mathbf{A}_{t}$, the simulated population time series will be exactly equal to the input data. We calculated elasticity by increasing recruitment (i.e. the respective elements of the Leslie matrix) by $1 \%$ in a single year $t$ and evaluated the effect of the perturbation on numbers of fish in the age classes exploited by fishing $(N)$ in year $t+X$. This was repeated for every year $t$ of the time series (except those that are less than $X$ years from the end of the time series). In order to compare species, we selected $X$ to be approximately equal to the specific generation time $\mu_{t}$ (the mean age of the parents of the offspring produced by a cohort over its lifetime; Caswell 2001). Thus, changes in recruitment at time $t$ will have time to be reflected in the mature population at time $t+X$. $\mu_{t}$ is calculated from $\mathbf{A}_{t}$ and is itself changing every year (Figs. S1 \& S2 in the Supplement).

Thus, the results of the perturbation depends not only on the year-specific transition matrices $\mathbf{A}_{t}$, but also on the age structure at the time of the perturbation, and the results differ from analyses of the elasticity of asymptotic growth rate (i.e. the first eigenvalue of $\mathbf{A}_{t}$ ).

Thereafter, elasticity is the sum of the elasticities due to recruitment for each year. For the generalized additive model (GAM) and generalized additive mixed model (GAMM) analyses, $\boldsymbol{e}_{\mathrm{t}}$ was logit transformed: $\log \left(\boldsymbol{e}_{\mathrm{t}} /\left(1-\boldsymbol{e}_{\mathrm{t}}\right)\right.$.

Note that in order to test whether the assumption of homogeneous fecundity can affect our results on population growth we have also calculated the population growth for each stock replacing abundance by biomass, without finding any significant differences in the results. We have therefore decided to keep the $\boldsymbol{e}_{\mathrm{t}}$ obtained from abundance.

\section{Statistical analysis}

To investigate the effect of climate, anthropogenic pressure and the intrinsic demography in shaping stocks' elasticity to recruitment, we combined stock-specific analyses with meta-analyses across all stocks. We related the temporal variability in each stock's elasticity to recruitment, $\boldsymbol{e}_{\mathrm{t}}$, to demo- 
graphic variables such as fishing mortality and mean age of the spawning stock, as well as to each stock's specific environmental variables (both regional and large-scale climate indices) using GAM formulations as implemented in the mgcv library of R 2.11.1 (Wood \& Augustin 2002). The rationale for also looking at the effect of environmental variables, which only indirectly affect $\boldsymbol{e}_{\mathrm{t}}$, is that these variables may influence several demographic variables simultaneously, including natural mortality, which is unknown in our study. To smooth the resulting relationship, we set the maximum degrees of freedom for each smooth term to 2 (i.e. $k=3$ ). We applied a backward selection strategy of GAM regressions based on minimisation of the generalized cross-validation criterion (GCV), and a measure of the proportion of variance explained (using unbiased estimators), $\mathrm{R}^{2}$. A covariate was retained if its removal decreased GCV without affecting $\mathrm{R}^{2}$ (Green \& Silverman 1994). To model $\boldsymbol{e}_{\mathrm{t}}$ for all the stocks in one model, we used a GAMM formulation (GAMM in the mgcv library). As explanatory variables we used $\mu, F$ and SST (SST and ST alike). We thus added to the GAM formulation (fixed effects) as described above a random effect (stock names, years) to take into account the specific effect of the stocks and of the years data were sampled. Akaike's information criterion (AIC) values were used to select the best model instead of GCV because the latter does not account properly for the random effect. We found no auto-correlation (using the ACF function) in the residuals of the selected models. No significant correlation was found between covariates.

\section{RESULTS}

Time series of fish abundance, generation time $\mu$, fishing mortality $F$, per-capita population growth rate and transient elasticity $\boldsymbol{e}_{\mathrm{t}}$ for hake, cod and pollock stocks are presented in the supplementary material (Figs. S1 \& S2). All the stocks showed a general temporal decrease in population numbers within the study period; this was more pronounced for NA hake, SA hake, NS cod and GOA pollock. The SA hake, NA hake and NEA cod stocks showed a decrease in $\mu$, indicating a progressive and directional change in their age structure. These 3 stocks displayed an increase in the transient elasticity to recruitment with time, and indicated an increasing contribution of recruitment success to the population growth rate.

\section{Elasticity analysis of recruitment changes}

Table 2 displays the best stock-specific GAMs selected based on the minimisation of the GCV values (see Table S1 in the Supplement). The explained variance ranged from $16.6 \% \mathrm{NS}$ cod to $68.8 \%$ for SA hake (Table 2, see Figs. S3 \& S4 in the supplement; www.int-res.com/articles/suppl/m480p277_supp.pdf). We note that a decrease in the $\mu$ of the stock led to an increase in the elasticity to recruitment for the hake (3 stocks considered to be over-harvested), the NEA cod stock and the GOA pollock stock. Likewise, an increase in the fishing mortality led to an increase in the elasticity to recruitment for the EBS pollock stock as well as for the 2 cod stocks.

For all stocks, the elasticity to recruitment $\boldsymbol{e}_{\mathrm{t}}$ was affected by the local environmental covariates, i.e. sea temperature. However, the shape and direction of the effect of sea temperature varied among stocks (Figs. S3 \& S4 in the Supplement, Table 2). The regional hydroclimatic conditions such as UI influenced the SA hake stock, while large-scale climatic phenomena such as wPDO and wNAO influenced the 2 pollock stocks and the NS cod stock, respectively.

Table 2 also displays the best GAMM selected based on the minimisation of the AIC values (see Table S1 in the Supplement). The best GAMM showed that a decrease of the generation time $\mu$ of the stock led to an increase in the elasticity to recruitment (Fig. 2A) as did a decrease of the fishing mortality, albeit to a lesser extent (Fig. 2B). Looking at average values per stock, elasticity to recruitment was negatively related to the generation time of the stock ( $\mu$ averaged over time) (Fig. 2C). The stocks displaying smaller averaged $\mu$ also displayed a greater mean elasticity to recruitment (linear model, $F$-statistic $\left.F_{1,5}=35.12, \mathrm{p}<0.002, \mathrm{R}^{2}=0.88\right)$, as growth rate depends more on recruitment for stocks with less mature age classes. The elasticity to recruitment was positively related to the mean fishing mortality (Fig. 2D). This relationship that was not significant (linear model, logit transformed $\boldsymbol{e}_{\mathrm{t}}=-2.08+0.64 F$, $F$-statistic $\left.F_{1,5}=0.53, \mathrm{p}=0.50, \mathrm{R}^{2}=0.10\right)$ and remained so when removing NEA cod, although the relationship was much improved (linear model, logit transformed $\boldsymbol{e}_{\mathrm{t}}=-2.08+0.99 F, F$-statistic $F_{1,4}=4.88$, $\left.\mathrm{p}=0.09, \mathrm{R}^{2}=0.55\right)$. Note that the relationship shown in Fig. 2D is inverse to the one shown in Fig. 2B (GAMM result on yearly data). Mean generation time was negatively related to mean fishing mortality when NEA cod was not taken into account (Fig. 2E). This relationship, which was not significant (linear 
Table 2. Results of generalized additive models (GAMs) on transient elasticity of the population growth to recruitment change. $s(X$, edf $=y)$ is the smoothing term, where $X$ represents the explanatory variable and $y$ is the estimated degrees of freedom (edf) of the smoothing term. When edf is 1 , the relationship is linear. The general sense of the relationship is indicated with (+) and $(-),(+,-)$ or $(-,+)$ for quadratic relationships. p-values for each variable are indicated $\left({ }^{* * *} \mathrm{p}<0.001,{ }^{* *} \mathrm{p}<0.01,{ }^{*} \mathrm{p}<0.05\right.$, $\left.{ }^{\top} \mathrm{p}<0.1\right)$. Dev: proportion of the null deviance explained by the model. NEA: Northeast Arctic; NS: North Sea; EBS: Eastern Bering Sea; GOA: Gulf of Alaska; NA: Northern Atlantic; SA: Southern Atlantic; BI: Balearic Islands; $\mu$ : mean age of the parents of the offspring produced by a cohort over its lifetime (generation time); F: fishing mortality for different age range as indicated; wPDO: winter Pacific Decadal Oscillation; UI: upwelling index, a regional hydro-climatic index; SST: sea surface temperature $\left({ }^{\circ} \mathrm{C}\right)$ with 'wint' for winter and for GOA 'sum1' for summer at Location 1 and 'wint2' for winter at Location 2; ST: sea temperature at $0-200 \mathrm{~m}$ depth

\begin{tabular}{|c|c|c|c|c|c|c|c|}
\hline Stock & Intercept & $\begin{array}{l}\text { Generation } \\
\text { time }\end{array}$ & $\begin{array}{l}\text { Fishing } \\
\text { mortality }\end{array}$ & $\begin{array}{l}\text { Climate } \\
\text { index }\end{array}$ & $\begin{array}{l}\text { Sea tempera- } \\
\text { ture } 1\end{array}$ & $\begin{array}{l}\text { Sea tempera- } \\
\text { ture } 2\end{array}$ & $\operatorname{Dev}(\%)$ \\
\hline SA hake & $-1.45 \pm 0.04^{* * *}$ & $\begin{array}{c}\mu^{* * *} \\
\text { edf }=1 \\
(-)\end{array}$ & & $\begin{array}{c}\text { UI } \\
\text { edf }=1.72 \\
(+,-)\end{array}$ & $\begin{array}{l}\mathrm{SST}_{\text {wint }} \\
\mathrm{edf}=1 \\
(+)\end{array}$ & & 68.8 \\
\hline NA hake & $-1.59 \pm 0.03^{* * *}$ & $\begin{array}{l}\mu \\
\text { edf=1 } \\
(-)\end{array}$ & & & $\begin{array}{c}\mathrm{SST}_{\text {wint }}{ }^{\mathrm{T}} \\
\mathrm{edf}=1 \\
(-)\end{array}$ & $\begin{array}{c}\mathrm{SST}_{\text {spring }}{ }^{*} \\
\text { edf }=1 \\
(+)\end{array}$ & 51.6 \\
\hline BI hake & $-1.44 \pm 0.06^{* * *}$ & $\begin{array}{c}\mu^{*} \\
\operatorname{edf}=1.77 \\
(-,+)\end{array}$ & & & $\begin{array}{c}\mathrm{SST}_{\text {wint }} \\
\text { edf }=1.56 \\
(-,+)\end{array}$ & & 39.1 \\
\hline NEA cod & $-2.75 \pm 0.08^{* * *}$ & $\begin{array}{l}\mu^{*} \\
\text { edf }=1 \\
(-)\end{array}$ & $\begin{array}{c}F_{5-10} \mp \\
\text { edf }=1.66 \\
(+)\end{array}$ & & $\begin{array}{c}\mathrm{ST}^{*} \\
\mathrm{edf}=1.17 \\
(+)\end{array}$ & & 41.4 \\
\hline NS cod & $-1.17 \pm 0.09^{* * *}$ & & $\begin{array}{c}F_{2-4} \mathrm{\Psi} \\
\mathrm{edf}=1 \\
(+)\end{array}$ & $\begin{array}{c}\text { wNAO } \\
\text { edf }=1.65 \\
(-,+)\end{array}$ & $\begin{array}{c}\mathrm{SST}_{\text {spring }} \\
\mathrm{edf}=1 \\
(-)\end{array}$ & & 16.6 \\
\hline EBS pollock & $-1.60 \pm 0.12^{* * *}$ & & $\begin{array}{c}F_{6-10} \\
\text { edf }=1 \\
(+)\end{array}$ & $\begin{array}{c}\mathrm{wPDO}^{*} \\
\mathrm{edf}=1 \\
(-)\end{array}$ & $\begin{array}{c}\mathrm{SST} \\
\mathrm{edf}=1 \\
(-)\end{array}$ & & 37.0 \\
\hline GOA pollock & $-2.35 \pm 0.22^{* * *}$ & $\begin{array}{l}\mu \\
\text { edf=1 } \\
(-)\end{array}$ & & $\begin{array}{c}\text { wPDO } \\
\text { edf }=1.81 \\
(-,+)\end{array}$ & $\begin{array}{c}\mathrm{SST}_{\text {wint2 }}{ }^{*} \\
\mathrm{edf}=1 \\
(-)\end{array}$ & $\begin{array}{c}\mathrm{SST}_{\text {sum1 }} \\
\mathrm{edf}=1.78 \\
(+)\end{array}$ & 45.0 \\
\hline All stocks ${ }^{\mathrm{a}}$ & $-1.81 \pm 0.04^{* * *}$ & $\begin{array}{c}\mu^{* * *} \\
\mathrm{edf}=1.64 \\
(-)\end{array}$ & $\begin{array}{c}F^{* *} \\
\mathrm{edf}=1 \\
(-)\end{array}$ & & & & \\
\hline
\end{tabular}

model, F-statistic $F_{1,5}=2.56, \mathrm{p}=0.227$ ), became highly significant when removing the NEA cod stock (linear model, $\mu=7.11-4.42 F$, $F$-statistic $F_{1,4}=39.06$, $\left.\mathrm{p}<0.01, \mathrm{R}^{2}=0.90\right)$. It showed that the more exploited stocks have shorter generation times, which may be linked to a narrower age structure, suggesting an effect of exploitation on the demographic characteristics of the stock, with the noticeable exception of NEA cod.

\section{DISCUSSION}

In this comparative study on 7 gadoid stocks, we showed spatial similarities and dissimilarities of the effect of climate, fishing and demographic structure on the elasticity of the population growth rate to recruitment. In other words, the ecological mecha- nisms shaping the contribution of recruitment to the growth rate differ across systems, while common general patterns have been identified.

\section{Effects of harvesting}

The 7 stocks studied displayed differences in the elasticity of the population growth to recruitment that were linked to the level of exploitation, though the strength and direction of the relationship varied with the level of the hierarchy and the scale of the analyses performed. On an intra-stock basis, the northern species ( 2 cod and 1 pollock stock) showed a significant positive effect of fishing on the elasticity to recruitment (Table 2), whereas the 3 hake stocks, which are all considered to be overharvested (ICES 2009), did not. The overall analyses showed that the 

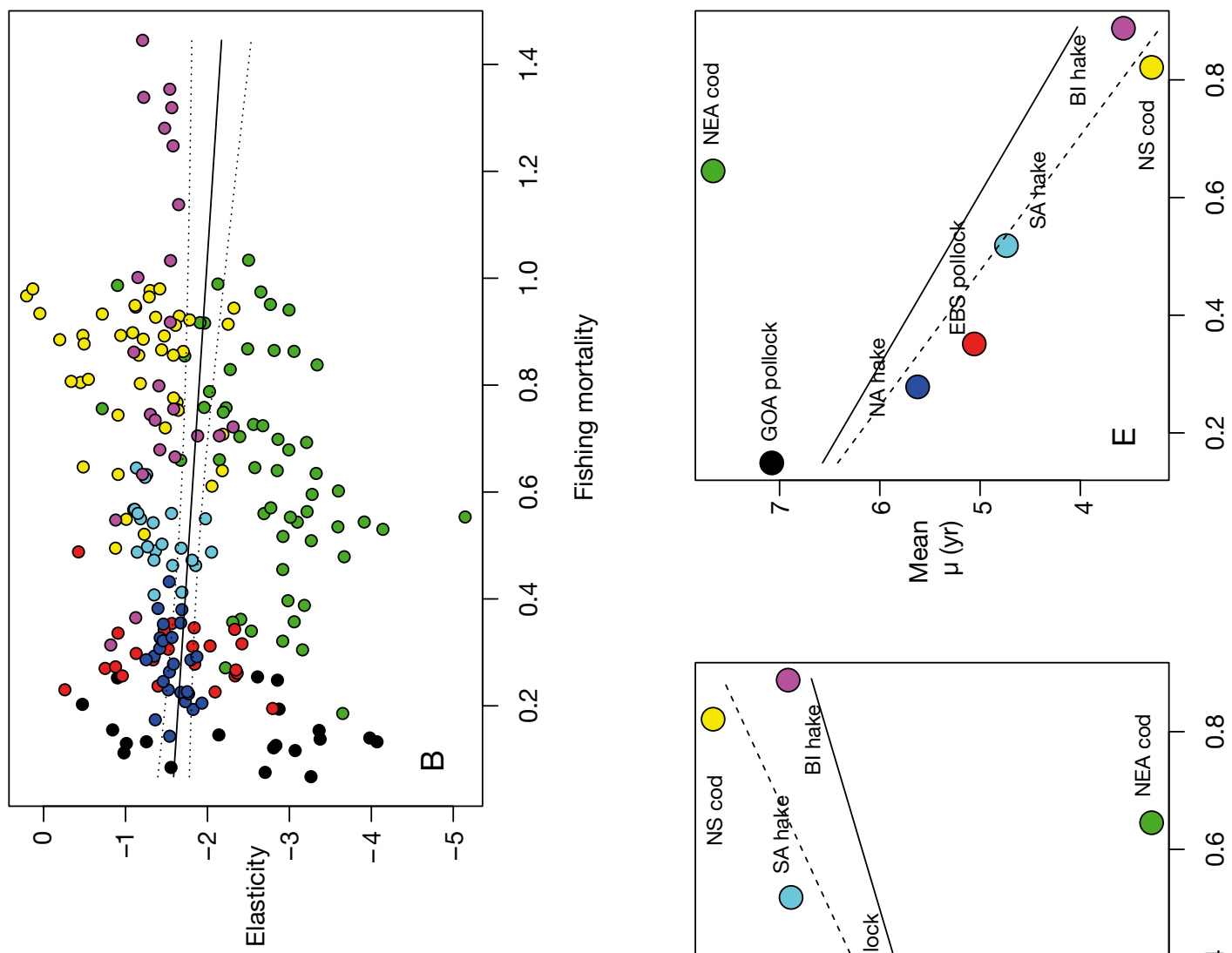

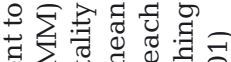

还

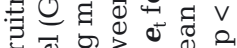

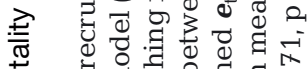

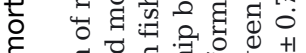

(ี

क ? वे

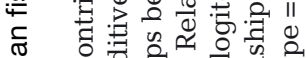

$\stackrel{\mathbb{\infty}}{\Sigma}$

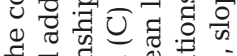

Ð త)

ฮี

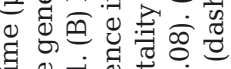

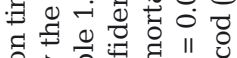

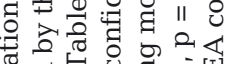

ช

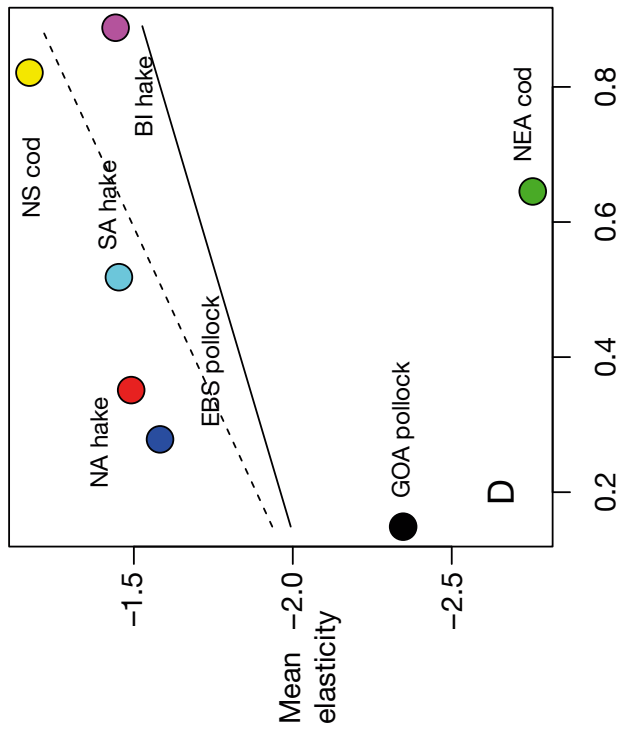

设

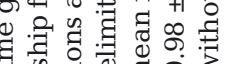

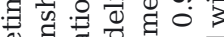

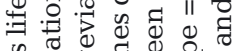

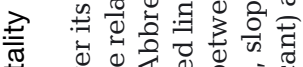

元

क त्व

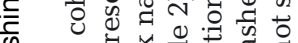

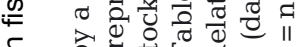
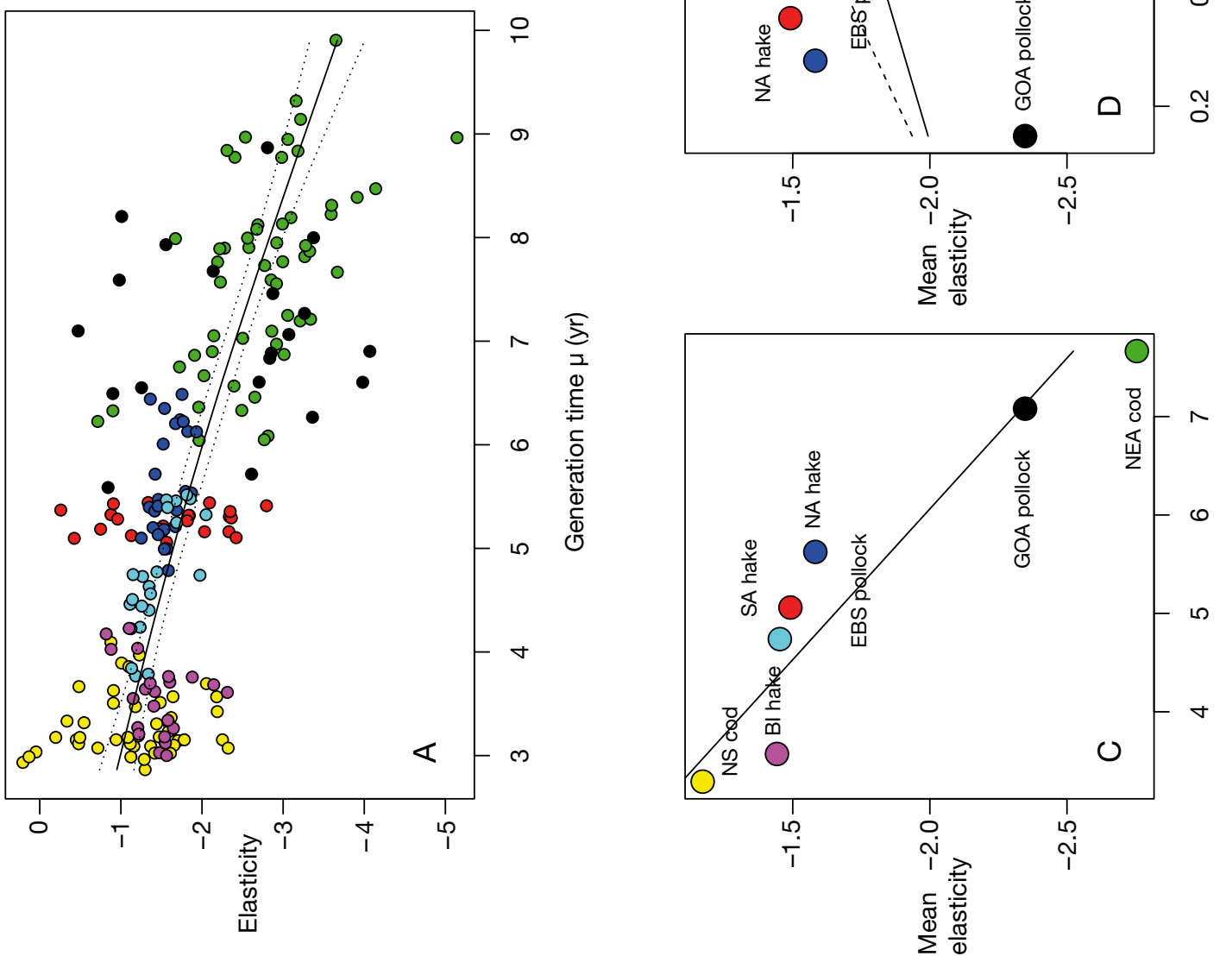

ช. ठ

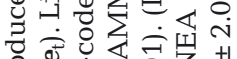

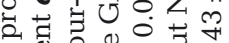

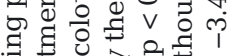

药

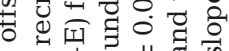

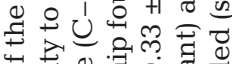

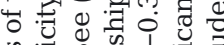

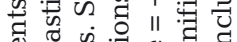

बत्व

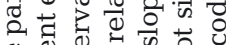

.

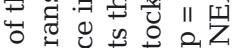

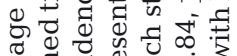

हี हี

$=00000$

$\stackrel{\frac{1}{\mathbb{N}}}{\Sigma}$

శี

ब

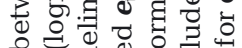

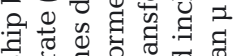

ปี

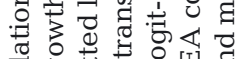

ब

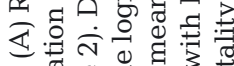

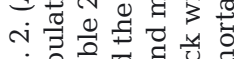

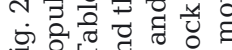


within-stock effect of fishing mortality $F$ was weakly negative (Fig. 2B) whereas the between-stock effect of mean $F$ appeared to be generally quite strongly positive, with NEA cod being a notable exception (Fig. 2D). Thus, among stocks and within 2 of the species (cod and hake), an increase in elasticity with $F$ was found, in agreement with theory, whereas the reverse pattern observed in the global model (Fig. 2B) seemed counterintuitive. We suggest that historically heavily exploited stocks with low $\mu$ have a lower capacity to change their productivity and hence their growth rate compared with stocks that are historically less exploited (e.g. GOA pollock) or that have retained a broader demographic structure in spite of exploitation (e.g. NEA cod and NA hake). In other words, the long-term effect of fishing may affect how the fish respond to short-term variations changes in $F$. These results highlight the importance of measuring these types of patterns at several scales in order to make the correct inference about the effects of management on stock demography.

\section{Effects of generation time and combined effects with harvesting}

While all stocks have been exploited for a long time, geographical differences were found, with a general tendency to higher mean $\mu$ for the northern stocks of the same species (Fig. 2C).

Overall, the elasticity to recruitment was mainly shaped by changes in $\mu_{\text {; }}$ the longer the generation time, the lower the elasticity to recruitment (Fig. 2A,C). On an intra-stock basis, the temporal variations in the elasticity to recruitment did not always appear to be related to those in $\mu$ (Table 2). Indeed, whereas a strong negative effect of $\mu$ on the elasticity was found for the SA hake and NEA cod stocks, these effects were weak for the NA hake and GOA pollock stocks and were not present for the EBS pollock and NS cod stocks. Note that for the BI hake stock the effect of $\mu$ on the elasticity to recruitment was nonlinearly positive.

Our results suggest that changes in $\mu$ likely had a larger effect on the elasticity to recruitment for the more exploited stocks (Fig. 2E), which may have been induced by a long-lasting demographic truncation and fishery-induced evolutionary change (Olsen et al. 2004). In this respect, the NEA cod seemed to be a counter example with a strong effect of $\mu$ on the elasticity to recruitment, despite being considered to be quite healthy (ICES 2011a). However, the NEA cod stock shows as much of an effect of $\mu$ on elasticity as the hake stocks that are thought to be overexploited (ICES 2009). Note that the effect of $\mu$ on the elasticity might be reduced if we were to use same time-series length for NEA cod as we used for hakes, only 2 to 3 decades. This suggests that age truncation and over-exploitation are not concomitant patterns, though they are often linked.

\section{Effects of the environment and geographic location of the stocks}

Several studies have demonstrated that stocks located at the limits of a species' geographical distribution are more sensitive to environmental variability (Brunel \& Boucher 2006) and that these limits are moving with climate change. The reduction in both the spatial heterogeneity and spatial distribution of spawning stocks has been suggested to decrease population stability (Hsieh et al. 2008, Hsieh et al. 2010, Ciannelli et al. 2013, this Theme Section). In this study, 2 stocks at the northern limit of the species' geographical distribution (EBS pollock and NEA cod) were studied over 3 decades, and both displayed an effect of temperature, albeit inversed. The positive effect of temperature on the NEA cod stock elasticity occurred concomitantly to the long-term change in age structure (Ottersen et al. 2006, Rouyer et al. 2011) and in spatial distribution (Opdal 2010). Note that although the NEA cod stock displayed a $50 \mathrm{yr}$ decrease in $\mu$ and in abundance, it is still considered to be in good health (ICES 2011a) due to improved management and strong and stable recruitment since the 90s). However, the negative effect of temperature on the elasticity of EBS pollock may constitute a more direct and short-term influence of the complex mesoscale processes that favour the success of the recruitment in the Bering Sea (see review by Hunt et al. 2011). This may explain the strong negative effect of PDO on this stock elasticity (Table 2). In other words, during low PDO years (i.e. when it is cold), the pollock stock is more linked to recruitment variability rather than to population survival. There was only one stock at the southern limit of the species' geographical distribution (NS cod) that was studied over 4 decades. In contrast to NEA cod, the NS cod stock displayed a negative effect of temperature on recruitment (e.g. Hjermann et al. 2013). A positive effect of SST on NA and SA hake elasticity was shown in increased larval survival, which thus favoured recruitment success (Goikoetxea 2011, Hidalgo et al. 2012). Similar to Hidalgo et al. (2012), we found evidence for environ- 
mental effects on the elasticity to recruitment for SA hake (upwelling during summer and winter temperature) (Domínguez-Petit et al. 2008) and (winter SST) for BI hake (Hidalgo et al. 2011)

The 2 studied pollock stocks displayed opposite effects of SST on the elasticity to recruitment (Table 2) that can be explained by the much lower temperature in the Bering Sea (SST May to July) compared with the Gulf of Alaska $\left(\mathrm{SST}_{\text {sum1 }}\right.$ June to August). In those areas, the climate effects could also trigger changes in trophic interactions, such as the recruitment of competitive species, or changes in spatial distribution (Bailey 2000, Ciannelli et al. 2005). For example, in the Gulf of Alaska it is well accepted that the decline in pollock recruits is driven by increased predation on small pollock by arrowtooth flounder Atheresthes stomias, which is now dominant in terms of biomass in that system (A'mar et al. 2010). In the Bering Sea, changes in pollock recruitment could be also be driven by changes in arrowtooth flounder distribution, but to a lesser extent since in the Bering Sea, pollock, skates and sharks all prey on arrowtooth flounder (Ianelli et al. 2009).

In conclusion, our comparative study on gadoid stocks across ecosystems illustrates how extrinsic variables shape the specific strategies used by the different species and their response to a decrease in generation. Our findings emphasise how the elasticity to recruitment can be affected by a long-term change in age structure of the population (perhaps due to fishing; Hidalgo et al. 2011, 2012, Rouyer et al. 2011, but see Ottersen et al. 2013, this Theme Section), but can also be directly affected by the ongoing fishing intensity. The elasticity of the population growth rate to recruitment cannot thus be solely explained by the age structure or the fishing intensity. To determine the elasticity, both parameters are needed.

Acknowledgements. We thank The Research Council of Norway (RCN) for funding the workshop Tropharct through the MICO project (grant no. 186310, Match/Mismatch and Ecosystem). This work is associated with the IMBER regional program, Ecosystem Studies of Sub-Arctic Seas (ESSAS). We are greatly in debt to all the people who collected the data used in the study and made them available to us. J.M.D., A.M.E. and D.Ø.H. acknowledge the support from the RCN through the ADMAR project (grant no. 200497/130). M.H. received support from Marie Curie IntraEuropean fellowship (IEF, FP7-PEOPLE-IEF-2008; project No 236549). L.C. acknowledges the support from the National Science Foundation - Research Coordination Network grant no. 1140207. We thank Leif-Christian Stige for comments and advice. We are indebted to Valerio Bartolino and Martin Lindegren and 3 anonymous referees who reviewed an earlier version of this article.

\section{LITERATURE CITED}

A'mar ZT, Punt AE, Dorn MW (2010) Incorporating ecosystem forcing through predation into a management strategy evaluation for the Gulf of Alaska walleye pollock (Theragra chalcogramma) fishery. Fish Res 102:98-114

Bailey KM (2000) Shifting control of recruitment of walleye pollock Theragra chalcogramma after a major climatic and ecosystem change. Mar Ecol Prog Ser 198:215-224

$>$ Brander KM (1995) The effect of temperature on growth of Atlantic cod (Gadus morhua L). ICES J Mar Sci 52:1-10

> Brunel T, Boucher J (2006) Pattern of recruitment variability in the geographical range of the exploited northeast Atlantic fish species. J Sea Res 55:156-168

Caswell H (2001) Matrix population models: construction, analysis, and interpretation, 2nd edn. Sinauer Associates, Sunderland, MA

Caswell H (2007) Sensitivity analysis of transient population dynamics. Ecol Lett 10:1-15

> Ciannelli L, Chan KS, Bailey KM, Stenseth NC (2004) Nonadditive effects of the environment on the survival of a large marine fish population. Ecology 85:3418-3427

> Ciannelli L, Bailey KM, Chan KS, Belgrano A, Stenseth NC (2005) Climate change causing phase transitions of walleye pollock (Theragra chalcogramma) recruitment dynamics. Proc Biol Sci 272:1735-1743

> Ciannelli L, Fisher JAD, Skern-Mauritzen M, Hunsicker ME, Hidalgo M, Frank KT, Bailey KM (2013) Theory, consequences and evidence of eroding population spatial structure in harvested marine fishes: a review. Mar Ecol Prog Ser 480:277-243

> Cury PM, Shin YJ, Planque B, Durant JM and others (2008) Ecosystem oceanography for global change in fisheries. Trends Ecol Evol 23:338-346

> Domínguez-Petit R, Korta M, Saborido-Rey F, Murua H, Sainza M, Piñeiro C (2008) Changes in size at maturity of European hake Atlantic populations in relation with stock structure and environmental regimes. J Mar Syst 71:260-278

Dorn M, Aydin K, Barbeaux S, Guttormsen M, Spalinger K, Wilkins M (2010) Assessment of the walleye pollock stock in the Gulf of Alaska. NPFMC Gulf of Alaska SAFE:53-156

FAO-GFCM (2009) Report of the eleventh session of the Scientific Advisory Committee. GFCM, Marrakech

> Fromentin JM, Fonteneau A (2001) Fishing effects and life history traits: a case study comparing tropical versus temperate tunas. Fish Res 53:133-150

Goikoetxea N (2011) Influence of the northeastern Atlantic oceano-meteorological variability on the northern hake (Merluccius merluccius). Analysis of the 1978-2006 period. University of the Basque Country, Bilbao

Green PJ, Silverman BW (1994) Nonparametric regression and generalized linear models: a roughness penalty approach. Chapman \& Hall/CRC, London

> Hallett TB, Coulson T, Pilkington JG, Clutton-Brock TH, Pemberton JM, Grenfell BT (2004) Why large-scale climate indices seem to predict ecological processes better than local weather. Nature 430:71-75

> Hastings A, Botsford LW (2006) A simple persistence condition for structured populations. Ecol Lett 9:846-852

Hidalgo M, Tomas J, Moranta J, Morales-Nin B (2009) Intraannual recruitment events of a shelf species around an island system in the NW Mediterranean. Estuar Coast Shelf Sci 83:227-238 
Hidalgo M, Rouyer T, Molinero JC, Massutí M, Moranta J, Guijarro B, Stenseth NC (2011) Synergistic effects of fishing-induced demographic changes and climate variation on fish population dynamics. Mar Ecol Prog Ser 426:1-12

Hidalgo M, Rouyer T, Bartolino V, Cerviño S and others (2012) Context-dependent interplays between truncated demographies and climate variation shape the population growth rate of a harvested species. Ecography 35: 637-649

Hjermann DØ, Stenseth NC, Ottersen G (2004) The population dynamics of Northeast Arctic cod (Gadus morhua) through two decades: an analysis based on survey data. Can J Fish Aquat Sci 61:1747-1755

$>$ Hjermann DØ, Fisher JAD, Rouyer T, Frank KT, Stenseth NC (2013) Spatial analysis of North Sea cod recruitment: concurrent effects of changes in spawning stock biomass, temperature and herring abundance. Mar Ecol Prog Ser 480:263-275

> Hsieh CH, Reiss CS, Hewitt RP, Sugihara G (2008) Spatial analysis shows that fishing enhances the climatic sensitivity of marine fishes. Can J Fish Aquat Sci 65:947-961

> Hsieh CH, Yamauchi A, Nakazawa T, Wang WF (2010) Fishing effects on age and spatial structures undermine population stability of fishes. Aquat Sci 72:165-178

Hunt GL, Coyle KO, Eisner LB, Farley EV and others (2011) Climate impacts on eastern Bering Sea foodwebs: a synthesis of new data and an assessment of the Oscillating Control Hypothesis. ICES J Mar Sci 68:1230-1243

Hurrell JW, Deser C (2009) North Atlantic climate variability: the role of the North Atlantic Oscillation. J Mar Syst 78:28-41

Ianelli JN, Barbeaux S, Honkalehto T, Kotwicki S, Aydin K, Williamson N (2009) Assessment of the walleye pollock stock in the Eastern Bering Sea. NPFMC Bering Sea and Aleutian Islands SAFE:49-147

ICES (2009) Report of the Working Group on the Assessment of Southern Shelf Stocks of Hake, Monk, and Megrim [WGHMM], 5-11 May 2009. ICES, Copenhagen, ICES CM 2009/ACOM 08

ICES (2011a) Report of the Arctic Fisheries Working Group (AFWG), 28 April-4 May 2011, Hamburg, Germany. ICES, Copenhagen, ICES CM 2011/ACOM 05

ICES (2011b) Report of the Working Group on the Assessment of Demersal Stocks in the North Sea and Skagerrak (WGNSSK), 4-10 May 2011. ICES, Copenhagen, ICES CM 2011/ACOM 13

Kalnay E, Kanamitsua M, Kistlera R, Collins W and others (1996) The NCEP/NCAR 40-year reanalysis project. Bull Am Meteorol Soc 77:437-471

Lassen H, Medley P (2001) Virtual population analysis-a practical manual for stock assessment. FAO Fish Tech Pap 400. FAO, Rome

Lavín A, Díaz del Río G, Cabanas JM, Casas G (1991) Afloramiento en el noroeste de la Península Ibérica. Indices de Afloramiento para el punto $43^{\circ} \mathrm{N} 11^{\circ} \mathrm{W}$. Período 1966-1989. Inf Tec Inst Esp Oceanogr 91:1-40

Le Maho Y, Durant JM (2011) Impacts of climate change on marine ecosystems. In: Vidas D, Schei PJ (eds) The world ocean in globalisation: climate change, sustainable fisheries, biodiversity, shipping, regional issues. Brill, Martinus Nijhoff Publishers, Leiden, p 133-146

> Leslie PH (1945) On the use of matrices in certain population mathematics. Biometrika 33:183-212

> Massutí E, Monserrat S, Oliver P, Moranta J and others (2008) The influence of oceanographic scenarios on the population dynamics of demersal resources in the western Mediterranean: hypotheses for hake and red shrimp off the Balearic Islands. J Mar Syst 71:421-438

Miller JM, Burke JS, Fitzhugh GR (1991) Early life history patterns of Atlantic North American flatfish: likely (and unlikely) factors controlling recruitment. Neth J Sea Res 27:261-275

Monserrat S, Marcos M, López-Jurado J (2008) Interannual variability of Winter Intermediate Water at the Balearic Islands. J Mar Syst 71:413-420

> Mueter FJ, Bond NA, Ianelli JN, Hollowed AB (2011) Expected declines in recruitment of walleye pollock (Theragra chalcogramma) in the eastern Bering Sea under future climate change. ICES J Mar Sci 68:1284-1296

> Murphy GI (1968) Pattern in life history and the environment. Am Nat 102:391-403

> Olsen EM, Heino M, Lilly GR, Morgan MJ, Brattey J, Ernande B, Dieckmann U (2004) Maturation trends indicative of rapid evolution preceded the collapse of northern cod. Nature 428:932-935

Opdal AF (2010) Fisheries change spawning ground distribution of northeast Arctic cod. Biol Lett 6:261-264

> Ottersen G, Hjermann DO, Stenseth NC (2006) Changes in spawning stock structure strengthen the link between climate and recruitment in a heavily fished cod (Gadus morhua) stock. Fish Oceanogr 15:230-243

Ottersen G, Stige LC, Durant JM, Chan KS, Rouyer TA, Drinkwater KF, Stenseth NC (2013) Temporal shifts in recruitment dynamics of North Atlantic fish stocks: effects of spawning stock and temperature. Mar Ecol Prog Ser 480:205-225

> Rouyer T, Ottersen G, Durant JM, Hidalgo M and others (2011) Shifting dynamic forces in fish stock fluctuations triggered by age truncation? Glob Change Biol 17: 3046-3057

Stenseth NC, Ottersen G, Hurrell JW, Mysterud A and others (2003) Studying climate effects on ecology through the use of climate indices: the North Atlantic Oscillation, El Niño Southern Oscillation and beyond. Proc Biol Sci 270:2087-2096

Taylor AH (1995) North-south shifts of the Gulf Stream and their climatic connection with the abundance of zooplankton in the UK and its surrounding seas. ICES J Mar Sci 52:711-721

> Wood SN, Augustin NH (2002) GAMs with integrated model selection using penalized regression splines and applications to environmental modelling. Ecol Model 157:157-177

> Worm B, Myers RA (2003) Meta-analysis of cod-shrimp interactions reveals top-down control in oceanic food webs. Ecology 84:162-173 